\title{
From traits to life-history strategies: Deconstructing fish community composition across European seas
}

Pécuchet, Lauréne; Lindegren, Martin ; Hidalgo, Manuel; Delgado, Marina; Esteban, Antonio; Fock, Heino O.; Gil de Sola, Luis; Punzón, Antonio; Sólmundsson, Jón; Payne, Mark R.

\section{Published in:}

Global Ecology and Biogeography

Link to article, DOI:

10.1111/geb.12587

Publication date:

2017

Document Version

Peer reviewed version

Link back to DTU Orbit

Citation (APA):

Pécuchet, L., Lindegren, M., Hidalgo, M., Delgado, M., Esteban, A., Fock, H. O., Gil de Sola, L., Punzón, A., Sólmundsson, J., \& Payne, M. R. (2017). From traits to life-history strategies: Deconstructing fish community composition across European seas. Global Ecology and Biogeography, 26(7), 812-822.

https://doi.org/10.1111/geb.12587

\section{General rights}

Copyright and moral rights for the publications made accessible in the public portal are retained by the authors and/or other copyright owners and it is a condition of accessing publications that users recognise and abide by the legal requirements associated with these rights.

- Users may download and print one copy of any publication from the public portal for the purpose of private study or research.

- You may not further distribute the material or use it for any profit-making activity or commercial gain

- You may freely distribute the URL identifying the publication in the public portal 
1 From traits to life history strategies: deconstructing fish community composition across European Seas

3 Laurene Pecuchet ${ }^{1 *}$, Martin Lindegren ${ }^{1}$, Manuel Hidalgo ${ }^{2}$, Marina Delgado ${ }^{3}$, Antonio Esteban ${ }^{4}$, Heino O.

4 Fock ${ }^{5}$, Luis Gil de Sola ${ }^{6}$, Antonio Punzón ${ }^{7}$, Jón Sólmundsson ${ }^{8}$ and Mark R. Payne ${ }^{1}$

$5 \quad{ }^{1}$ Centre for Ocean Life, National Institute of Aquatic Resources (DTU-Aqua), Technical University of

6 Denmark, Charlottenlund Castle, DK-2920 Charlottenlund, Denmark

7 2Instituto Español de Oceanografía, Centro Oceanográfico de Baleares, Muelle de Poniente, s/n, Apdo. 291,

807015 Palma de Mallorca, Spain

9 IInstituto Español de Oceanografía, Centro Oceanográfico de Cádiz, Muelle de Levante, 11006 Cádiz, Spain

$10{ }^{4}$ Instituto Español de Oceanografía, Centro Oceanográfico de Murcia, Varadero 1, 30740 San Pedro del

11 Pinatar, Spain.

$12{ }^{5}$ Thuenen Institute of Sea Fisheries, Hamburg, Germany

13 'Instituto Español de Oceanografía, Centro Oceanográfico de Santander, Promontorio San Martín, 39080

14 Santander, Spain

15 'Instituto Español de Oceanografía, Centro Oceanográfico de Málaga, Puerto Pesquero, 29640 Fuengirola, 16 Spain

$17{ }^{8}$ Marine and Freshwater Research Institute, Skúlagata 4, PO Box 1390, 121 Reykjavík, Iceland

18 Email: Laurene Pecuchet laupe@aqua.dtu.dk, Martin Lindegren mli@aqua.dtu.dk, Manuel Hidalgo

19 im.hidalgo@ba.ieo.es, Marina Delgado marina.delgado@cd.ieo.es, Antonio Esteban

20 antonio.esteban@mu.ieo.es, Heino Fock heino.fock@thuenen.de, Luis Gil de Sola gildesola@ma.ieo.es,

21 Antonio Punzón antonio.punzon@st.ieo.es, Jón Sólmundsson jonsol@hafro.is and Mark Payne

22 mpay@aqua.dtu.dk

23 Keywords: community composition; marine fish; life history strategies; trait; trade-off; fecundity; size;

24 offspring survival; temperature; depth; archetypal analysis

25 Running title: Life history strategies of European fish communities

*corresponding author: Laurene Pecuchet, laupe@aqua.dtu.dk

Words in abstract: 300

Words in main body of the paper: 5,600

Number of references: 71 
31 Abstract

32 Aim

33 The life history of a species is determined by trade-offs between growth, survival and reproduction to 34 maximize fitness in a given environment. Following a theoretical model, we investigate whether the 35 36 37 38 39 40 composition of marine fish communities can be understood in terms of a set of life history strategies and whether the prevalence of the strategies follows specific spatial patterns that can be related to the environment.

\section{Location}

European Seas

\section{Methods}

An extensive set of scientific bottom trawl surveys were collected to obtain the species composition of fish communities across European Seas. We complemented this data with species-specific information regarding six life history traits, reflecting reproductive, growth and feeding modes. We then calculated the optimal number of strategies needed to summarize the information contained in the traits by using an archetypal analysis. The proportion of each obtained strategy in the communities and their spatial patterns were explained as a function of the environment and their temporal changes were investigated.

\section{Results}

The species could be decomposed into a continuum of three life history strategies: opportunistic, periodic and equilibrium, resulting from trade-offs between traits. The strategies' marked spatial patterns could be explained by depth, temperature and its seasonality, chlorophyll and fishing effort. In recent years, opportunistic and equilibrium strategies significantly increased, likely due to an increase in temperature and decrease in fishing effort.

\section{Main conclusions}

Our empirical analysis supports a theoretical framework outlining three life-history strategies of fish. The strategies vary predictably in space and time in response to the environment. This highlights the underlying process whereby fitness is optimized through trade-offs between growth, feeding and reproduction under different environmental conditions. Due to their response to the environment, life history strategies provide a suitable tool to monitor and understand community changes in response to natural and anthropogenic stressors, including fishing and climate change. 


\section{Introduction}

Trait-based study of biodiversity has been an expanding field in recent decades (Petchey \& Gaston 2002, Schleuter et al. 2010, Cadotte et al. 2013). Traits are often referred to as any characteristics of an individual, or a group of organisms, which encompass morphological, demographic or physiological attributes (Violle et al. 2007). Using traits instead of taxonomic information has several advantages when studying biodiversity since they provide a more fundamental and mechanistic approach to understanding community composition (Shipley et al. 2006, McGill et al. 2006, Pecuchet et al. 2016b). Trait-based approaches also permit to reduce the complexity of community diversity by focusing on the factors that best characterize an organism's fitness (Litchman et al. 2013) and has also been successfully related to ecosystem functions and services in the terrestrial (Diaz \& Cabido 2001, Flynn et al. 2011) and marine (Bellwood et al. 2003) realms.

Selecting a relevant set of key traits to characterize the species and ultimately the communities can, however, be difficult (Petchey and Gaston, 2006), especially when the aim is to explain ecosystem functions (Mclntyre et al. 1999, Lavorel \& Garnier 2002). In particular, deciding on how many traits to include is controversial since using too many traits increases complexity and may introduce redundancy due to correlation among closely related traits. Trait information can instead be reduced into combinations of particular trait values, so-called functional groups. Functional groups are defined as a unit of species sharing similar trait-attributes, for example body size and trophic guild (e.g Halpern \& Floeter 2008). However, adding new traits to this analysis can substantially increase the number of functional groups.

In contrast to functional groups, life history strategies are defined as a combination of trait attributes and are the result of inter-relationships and trades-offs among key traits (Winemiller et al. 2015). They are often based on a theoretical framework and are used to shed light on the evolution of the life history of organisms, as well as the environment wherein the species occur (Charnov et al. 2013). Some well-known examples of life history theories or models are the $r$ and K-selection (Pianka 1970) or the fast-slow life 
history continuum (Franco \& Silvertown 1996). Due to their simplicity, these linear models of life history strategies have been used in numerous studies ranging from population dynamics (e.g. Oli 2004) to communities spatial pattern (e.g. Wiedmann et al. 2014). However, this approach has also been criticized for oversimplifying reality (Nichols et al. 1976, Bielby et al. 2007).

For fish communities, Winemiller and Rose (1992) developed the "Equilibrium-Periodic-Opportunistic" (EPO) model. This theoretical model links three strategies characterized by trades-off between fecundity, juvenile survival and generation time to environmental stability and predictability: "equilibrium species" with high juvenile survivorship; "opportunistic species" with low generation time; and "periodic species" with high fecundity. The equilibrium strategy is thought to prevail in stable and predictable environments while the opportunistic strategy prevails in unstable and unpredictable environments. The periodic strategy is thought to occur in seasonal but periodically fluctuating environments. A number of studies have used the EPO model to investigate temporal changes and spatial distribution of the composition of freshwater fish communities (Mims \& Olden 2012).

In this study, we investigate whether marine fish species present in European Seas can be categorized into similar life history strategies based on their trait attributes. Furthermore, we investigate whether there are any consistent geographical and temporal patterns in the prevalence of life history strategies within fish communities across Europe and whether the patterns and trends can be explained by external (environmental) factors. For this analysis, the shelf seas of the North-east Atlantic provide an excellent study area since they contain pronounced natural gradients in terms of e.g. temperature, productivity and biodiversity, and are subjected to various anthropogenic pressures including fishing and eutrophication (Grizzetti et al. 2012). Furthermore, these seas are also rich in data, and therefore an ideal area to test the life history strategies hypothesis on the fish communities using standardized datasets with a high taxonomic and spatial resolution. 


\section{Bottom trawl surveys}

Fifteen scientific bottom trawl surveys covering ecosystems from the Mediterranean Sea to Greenland and spanning on average ten recent years (2002-2012) were collated (Appendix S1 in Supporting Information). As our focus was on offshore fish communities, and due to different survey sampling schemes, hauls sampled at a depth shallower than 20 meters were excluded to avoid the inclusion of coastal fish species. The refined data set contained approximately 20.000 individual hauls (i.e. stations) that lasted on average 30 minutes and covered 3 nautical miles. Not all surveys used the same taxonomic recording, therefore species scientific names were checked against the World Register of Marine Species and updated by the 'accepted' scientific name when appropriate. For some species that are difficult to identify, taxonomic recording was specified to the genus level. For each $1 / 2$ degree latitude and longitude cell covered by the surveys, we derived the relative abundances of all the species present, calculated as the sum of its abundance in all the hauls performed in a grid cell divided by the total abundance of all the species in that grid cell. The species' abundances were log transformed prior to the calculation. A species was noted present in a grid cell if it was ever recorded in one of the hauls performed in the grid. In order to study temporal changes in the prevalence of life history strategies, we calculated relative abundances and presence of species using the same method but for each year separately. Due to the limited time-span of many surveys, we restricted the temporal analysis to the North Sea where time series are available from 1980 onwards.

\section{Trait information}

Six traits were selected to cover the fundamental Darwinian objectives of an organism: to feed, survive and reproduce. These traits were also selected as they were previously used to describe the theoretical life history strategies of fish species based on the EPO model (Winemiller 2005, Mims et al. 2010). These traits are: maximum length, lifespan, trophic level, fecundity, offspring size and parental care. The first three 
traits were extracted from FishBase (Froese \& Pauly 2012). Maximum length (Lmax) represents the longest total length ever recorded for a given species. Lifespan is defined as the theoretical maximum expected age for a species and is estimated within FishBase using the growth (K) and length at infinity (Linf) parameters from the Von Bertalanffy growth equation. Linf is calculated from empirical growth data for the majority of the species but is inferred from Lmax for data-poor species, hence creating a dependency between these variables for some species in FishBase. Trophic level represents the position of a species in the food chain, ranging from a value of 2 when the diet is based on plant or detritus to 4.5 for top predators. Trophic level is primarily calculated from empirical diet studies or inferred from taxonomically related species. Fecundity is the average total number of offspring produced per mature female per year, usually calculated as the number of oocytes in the ovary. Fecundity can be either determinate, where the annual potential fecundity is set before the onset of the spawning season, or indeterminate, where the species continuously produces eggs during the spawning season and the annual potential fecundity is not fixed. Since information on fecundity type and the number of batches spawned per year is largely lacking, the average total number of offspring produced per year for batch spawners is likely underestimated. The offspring size corresponds to the average size of the offspring released in the water, i.e. eggs for oviparous or larvae/juveniles for ovoviviparous. Parental care relates to the investment of the parents in the survival of their offspring. Parental care was transformed from categorical to continuous values, using a similar approach to Winemiller (1989), as follow: (1) pelagic egg, (2) benthic egg, (3) hidden brood, (4) guarded brood and (5) bearer. These three traits values were primarily derived from literature (Pecuchet et al. 2016a). For each species, only one value per trait was used assuming that inter-species variability is higher than intra-species variability. There were approximately 600 unique species or genus recorded in the surveys. Out of these, 153260 species and 29 genera had complete information for all six traits and were used in the analysis. 154 Although representing only half of the entire species pool recorded in the surveys, the species retained 155 were the most frequently occurring and the most abundant. Hence, on average across all the $1 / 2$ degree grid cells, $95 \%$ of the species present and $97 \%$ of the individuals recorded in each grid cell had trait information. 


\section{Life history strategies}

159 We used the unsupervised learning method Archetypal analysis (AA) to characterize European marine fish species. AA is similar to a cluster analysis, but focuses on identifying extreme values that can be used as archetypes, rather than on the means or medians of the cluster (Cutler \& Breiman 1994). The core of the AA approach is the identification of points (archetypes) forming the corners of the convex hull volume encompassing the trait space (Mørup \& Hansen 2012): points are then represented by the proportions based on the proximity of the point to each archetype. AA has several advantages compared to traditional cluster analysis, such as k-mean and k-medoid since these can result in an arbitrary grouping of neighbouring points when the data are continuous. For example, two data points which are at the limits of the space defined by two clusters might be categorized differently. Instead, AA gives similar values to the points that are close to each other in traits space (Hart et al. 2015) resulting in a continuous grouping instead of a categorical (Cutler \& Breiman 1994). Therefore, AA is a suitable tool to identify atypical species in a dataset, which makes it useful to characterize life history strategies based on traits.

171 Trait data was normalized before input to AA by log10 transforming fecundity, offspring size, body size and 172 lifespan and then all six traits were standardized (i.e. to a mean of 0 and a variance of 1 ) to ensure equal weights in the AA. The AA was performed on the traits matrix for $k=1,2,3 \ldots 10$ fixed number of strategies and the residuals sum of squares (RSS) of 10 iterations was calculated for each $k$ using the package 'archetypes' in R (Eugster \& Leisch 2009). A robust, iteratively reweighted least squares fitting algorithm was used to down-weight the influence of the outliers (Eugster \& Leisch 2011). We used the 'elbow criterion' to select the optimal number of strategies permitting to minimize the RSS while minimizing the number of strategies. This is done visually by assessing the number corresponding to a significant drop in 
strategies was then mapped as a proportion weighted by the species relative abundances or based on species presence only. The proportions were calculated as the mean of each life history strategy from the species composition in each grid cell. Hence, each grid cell has: pLHS1 + pLHS2 + pLHS3 $=1$, where $p$ is the proportion of the corresponding life history strategy (LSH).

\section{Environmental predictors}

In order to explain the observed spatial patterns of the life history strategies, several environmental variables were collected. Annual, winter (January-March) and summer (July-September) mean sea temperature and salinity at the surface and bottom were obtained on a $1 / 4$ degree grid resolution from the World Ocean Atlas (www.nodc.noaa.gov/OC5/woa13) for the period 2005-2012 and averaged on a $1 / 2$ degree grid. Surface and bottom temperature seasonality was calculated as the difference between the summer and winter mean temperatures. Chlorophyll data, used as a proxy for primary production, were obtained from the GlobColour database (hermes.acri.fr) as monthly averages for the years 2002-2012 on a $1 / 2$ degree grid resolution. All the chlorophyll concentrations were log transformed prior to calculations. Several metrics were derived from the dataset, including mean annual chlorophyll concentration and mean chlorophyll concentration during spring, i.e. March to May. Furthermore, chlorophyll variability during the year (proxy for seasonality and resource stability) was calculated as the standard deviation of the mean chlorophyll concentration of each month across years, while variability of the chlorophyll concentration during the spring bloom (proxy for resource predictability) was estimated as the standard deviation of mean spring chlorophyll concentrations between years. Minimum, maximum and variability (standard deviation) of depth were obtained for each $1 / 2$ degree cell from ETOPO1 (www.ngdc.noaa.gov/mgg/global) whereas mean depth was calculated directly from the depth of the hauls performed.

Fishing has an important impact on the composition of a community by favouring small and fast growing species relative to large and slow growing species (Jennings et al. 1999b, De Juan et al. 2007, Sguotti et al. 2016). Fishing intensity can thus be an important variable explaining the spatial prevalence of the 
strategies. Unfortunately, extensive data on fishing effort is scarce and only available for a subset of the area. As a proxy for bottom fishing intensity, we used the ratio of the area of the seabed swept by bottom trawl fishing gear, derived from Vessel Monitoring System (VMS) intensity data (ICES 2015). The swept area ratio was calculated per $0.05^{\circ} \times 0.05^{\circ}$ grid cell per year for vessels greater than 12 meters in length, and can be interpreted as the percentage of grid cell-equivalent area swept per year. For this study, the swept area ratio was aggregated to the $1 / 2$ degree grid cell and averaged over the four years 2009-2012.

For the temporal case study in the North Sea, sea surface temperature data were gathered for the years 1980-2014 from a hydrographic analysis product (AHOI, Núñez-Riboni \& Akimova 2015). For each year, the mean temperature was calculated as the mean of all the months, and temperature seasonality was calculated as the difference between the summer and winter months. Fishing effort, calculated as the number of hours fished by beam trawlers or otter trawlers in the North Sea, was obtained for the years 1991-1995 and 2003-2012 (Jennings et al. 1999a, Engelhard et al. 2015).

\section{Modelling of the life history strategies}

The different species strategies emerge from life history evolution and as such their prevalence has been hypothesized to be non-randomly distributed and intimately linked to the environment (Grime, 1977; Winemiller and Rose, 1992). We hence tested the hypothesis that the prevalence of the life history strategies could be explained by environmental variables using generalized additive mixed models (gamm), which allows for curvilinear relationships between the response and explanatory variables (Wood 2006), e.g. in case of an environmental optimum or saturation, and permits to correct for spatial autocorrelation. In a prior analysis, we reduced the number of environmental variables to avoid problems with correlation among predictors and retained only unclustered or not highly correlated $(r<0.8)$ variables (Dormann et al. 2013). Eight abiotic variables were retained for the analysis: mean depth of the sampled hauls, maximum and variability of depth in each grid cell; mean and seasonality of sea surface temperature; mean and variability of annual chlorophyll concentration and sea surface salinity (Appendix S2). 
We modelled the life history strategies as a function of the abiotic variables. The life history strategies proportion were logit transformed prior to the analysis to normalize the data and then fitted as the response variable with a Gaussian (Normal) error distribution (Warton \& Hui 2011). Spatial auto-correlation was incorporated into this model with a Gaussian structure chosen from visual assessment of the variogram. The smoothing spline functions ( $s$ ) were constrained to four degrees of freedom $(k=4)$, allowing for third-order relationships, but restricting flexibility during model fitting. The strategy proportions were corrected for sampling effort by including the number of hauls performed in each grid cell as an additional explanatory variable smoother in each model and only grid cells with more than two hauls were included $(n=885)$. All the possible models containing from zero to a maximum of three environmental variables were fitted and evaluated using the package 'MuMIn' in R (Barton 2016) and the best model, i.e. defined as the one with the lowest Akaike's Information Criterion (AIC), was retained. For each strategy the predictors of the best model were plotted against the response variable. Standard model checking diagnostics were applied. We calculated the relative variable importance (RVI) to assess the contribution of each variable to the performance of the final multivariate gamm. RVI was quantified for each variable of the final models by randomly permuting the values of the variable of interest across grid cells and measuring the difference between the adjusted $r^{2}$ of the newly fitted model in comparison to the original model, i.e. measuring the drop in the quality of the model fit. Thus, a variable that caused a large decrease in model performance when randomized contributed greatly to the fit of the model.

247 To explore the potential impacts of fishing on the strategies' prevalence, a second model which integrated 248 both environmental variables and fishing intensity were performed on a sub-area of the study for which 249 fishing data was available. The same environmental variables used in the main model were tested as 250 explanatory variables alongside fishing intensity using the same gam modelling method. were modelled using a linear model corrected for first order temporal auto-correlation (i.e. AR1). 


\section{Results}

\section{Summarizing traits variability into life history strategies}

The optimal number of archetypes $(\mathrm{k})$ needed to encompass the spatial volume of trait-space was found to be three (Appendix S3). The largest drop in the RSS occurred when passing from two to three archetypes and adding a fourth one did not significantly reduce the RSS. The three corresponding life history strategies were represented in a biplot where the first two axes of the underlying principal component analysis (PCA) explained most of the trait variability (77\%, Fig. 1). The first axis (PC1) explained almost half of the total variability (45\%) and was driven by offspring size, maximum length, lifespan and trophic level. The second axis was driven by fecundity and parental care. Several traits were clustered (maximum length, lifespan and trophic level), while others were negatively correlated (fecundity against parental care and offspring size). The three life history strategies could be visualized as a triangle in trait space with each extreme point representing a unique combination of traits characteristics (Fig. 1). These strategies and their relations with traits corresponded closely with the theoretical model of Winemiller and Rose (1992), and are henceforth referred to as opportunistic, periodic and equilibrium strategies, respectively. The opportunistic strategy was characterized by species with small size, low trophic level and short lifespan but with relatively high fecundity and parental care, such as species of gobidae and ammodytidae, including the sand goby (Pomatoschistus minutus) and lesser sand eel (Ammodytes tobianus), as well as small pelagic fish, e.g., European anchovy (Engraulis encrasicolus). The periodic strategy was characterized by species with medium to high lifespan, length and trophic level, high fecundity but low parental care and offspring size, such as sunfish (Mola mola), conger eel (Conger conger) and several species of gadoids including blue ling (Molva dypteriga) and Atlantic cod (Gadus morhua). The equilibrium strategy was characterized by species with high length, lifespan and trophic level, low fecundity but large offspring size and high parental care, such as rays and sharks, e.g. marbled electric ray (Torpedo marmorata) and spiny dogfish (Squalus acanthias), as well as rabbitfish (Chimaera monstrosa). 
The species were not clustered around the three strategies end-points but instead demonstrated a continuum between the strategies (Fig. 1). A species could therefore have characteristics of more than one strategy at the same time, and were thus characterized by the proportions expressed in each strategy (Appendix S4). Both the opportunistic and the periodic strategies were prominent in the species pool, while few species showed an equilibrium strategy

\section{Patterns of life history strategies}

The distribution of life history strategies exhibited clear spatial patterns (Fig. 2). The proportion of the equilibrium strategy was generally much lower than the periodic and opportunistic strategies with values ranging between $0 \%$ and $36 \%$. On the contrary, the proportions of the periodic and opportunistic strategies were never lower than $25 \%$ and $23 \%$, and reached a maximum of $66 \%$ and $64 \%$, respectively. The proportion of the equilibrium strategy was highest at high latitudes, in Iceland and Greenland, as well as in the Balearic and Irish Seas. The opportunistic strategy displayed a North-West to South-East gradient, prevailing notably in the Baltic Sea, the southern North Sea and the Mediterranean while less abundant in Iceland and Greenland. The periodic strategy did not exhibit strong spatial patterns as it had a relative high prevalence in most of the studied area, notably south of Iceland, in the northern offshore of the North Sea and in the Celtic Sea.

We found the same overall spatial pattern when using presence data (Appendix S5) and the strategies prevalence in the communities calculated using abundance and presence were highly correlated. A notable change was a shift to a lower prevalence of the equilibrium strategies when using abundance compared to presence (Appendix S5). The spatial patterns were robust to different seasons, as seen for example in the North Sea (Appendix S6).

\section{Environmental predictors of life history strategies}

299 The best models with maximum three abiotic predictors explained $53 \%, 70 \%$ and $78 \%$ of the variability of 
and sea surface temperature seasonality (SST season) were retained in all the final models. SST was the variable explaining most of the variability in the opportunistic strategy, with a positive relationship, while it followed a negative relationship for the equilibrium strategy (Fig. 3). SST seasonality was the most important variable explaining the variability of the equilibrium strategy, and followed a negative relationship. On the other hand, the opportunistic strategy had a positive and saturating relationship with SST seasonality. Depth was also an important predictor of the equilibrium and periodic strategy, with a positive and hump-shape relationship, respectively. Chlorophyll concentration was also retained in the opportunistic strategy and followed a positive relationship. The same explanatory variables were found when using presence only, at the exception of the equilibrium strategy for which chlorophyll concentration was retained instead of depth (Appendix S5). For the subarea where both environmental variables and fishing intensity was available, the best predictors of the opportunistic strategy were depth, temperature and temperature seasonality, explaining $78 \%$ of the variability, while for the periodic strategy they were depth, temperature and chlorophyll, explaining $63 \%$ of the variability. For the equilibrium strategy, fishing intensity, depth and sea surface temperature were the most important variables explaining $48 \%$ of the variability with fishing demonstrating a negative relationship with prevalence (Appendix S7).

During the period 1980-2014 in the North Sea, the proportion of the periodic strategy declined $(p<0.001)$ while it increased for the equilibrium $(p<0.001)$ and opportunistic $(p<0.001)$ strategies. Although demonstrating significant temporal trends the magnitudes of change in prevalence were rather moderate, amounting to a decrease in the periodic strategy from $46 \%$ in 1980 to $38 \%$ in 2014 and an increase in the equilibrium and opportunistic strategies from $7 \%$ to $12 \%$ and $47 \%$ to $50 \%$, respectively. During the same time period SST increased $(p<0.01)$, whereas for the recent period $(1990-2012)$ fishing effort showed a marked decline, especially for beam trawlers $(p<0.05)$.

\section{Discussion}


Characterizing ecological communities by a set of biological traits is challenging since the selected traits are often correlated and therefore contain similar information. In this study, we show that several key traits of marine fish are correlated and that the variability of these traits could be reduced into three main components based on archetypal analysis (AA). AA has several advantages compared to traditional cluster analysis, especially when the data are continuous, as it gives similar values to the points that are close to each other in trait-space (Hart et al. 2015). Each point in the trait-space, e.g. a species, is defined as a convex combination (i.e. a proportion that sums to one) of the archetypes (in this case, the three life history strategies) rather than being assigned to a single class or cluster (Cutler \& Breiman 1994). Furthermore, the results of the AA are also easily interpretable thanks to the more pronounced contrasts fields, such as economics, astrophysics and pattern recognition for some years now (Bauckhage \& Thurau 2009) but has only recently been applied in biology and ecology (Hart et al. 2015). Using this novel approach the three main trait components identified are well in accordance with the theoretical model of Winemiller and Rose (1992), where the trait-space is encompassed by a triangular shape with endpoints corresponding to a life history strategy - opportunistic, equilibrium and periodic. At the community level the proportion of the strategies expressed followed a strong spatial pattern in the Europeans seas. These spatial patterns can be explained by the abiotic variables where each strategy prevails under different environmental conditions, largely depending on sea surface temperature and its seasonality, as well as depth. The prevalence of the strategies is not fixed through time, and the last 30 years have seen a slight increase in the opportunistic and equilibrium strategies in the North Sea while the periodic strategy has decreased. These changes paralleled a period of change in the abiotic environment of the North Sea, with an increase in temperature and a decrease in fishing effort.

For large species, two distinctive strategies were dominant: either the periodic strategy producing many small offspring at the cost of offspring survival, or the equilibrium strategy producing few large offspring but with high survival. The periodic strategy is composed mainly of bony fish species, e.g. large flatfish and 
gadoids species, while the equilibrium strategy is mainly composed of elasmobranchs, e.g. sharks and rays.

351

352

353

354

355

356

These strategies reflect the evolutionary and environmental constraint and trade-offs shaping variability in life history strategies (Neuheimer et al. 2015). High fecundity balances high pre-adult mortality while longevity balances unfavourable periods for reproduction in typical poor environmental conditions (Gunderson 1997, Longhurst 2002). In contrast to the large species, the small and short lived species, such as gobies and clupeids, largely followed the opportunistic strategy producing many small offspring. The lifetime reproductive value of these short lived species is often compensated by fast growth, early maturation and indeterminate spawning (Tsoukali et al. 2016). The simpler, and often used, slow-fast continuum model was not appropriate here and would have failed to explain some of the trait-variability. However, in smaller and extreme ecosystems or in smaller samples of species with a wide geographical range, the slow-fast continuum model can sufficiently explain the life history variation (Juan-Jordá et al. 2013, Wiedmann et al. 2014).

The strategies prevalence in the communities was linked to the environment and its variability. Notably, we found that the opportunistic strategy prevailed in environments with high temperature and strong temperature-seasonality while the equilibrium strategy prevailed in environments with lower and more stable temperatures. The opportunistic reproductive strategy, corresponding to the production of many small eggs, is favourable in seasonal environments to compensate for the short time where resources are available (Boyce 1979) and in warm environments to balance the higher egg mortality resulting from thermal stress (Pepin 1991). The strong negative relationship between the opportunistic strategy and temperature is verified by the recent distributional shift of mostly small and short-lived species in response to warming (Perry et al. 2005, Magurran et al. 2015), where these opportunistic seasonal migrants take advantage of newly disturbed conditions in these areas (Collie et al.,2008). The opportunistic species are physiological generalists; they are the first to respond to disturbance and can quickly attain high densities thanks to their life-history characteristics (e.g. high fecundity, short generation time and wide dispersal ability; Levinton 1970). The opportunistic strategy prevails in lower latitudes in areas with high thermal 
seasonality and primary productivity while the equilibrium species prevails in higher latitudes and in areas with comparatively lower seasonality. According to MacArthur (1960), the opportunistic species are considered not to be resource-limited and are thriving in environment where the population size is below the carrying capacity of the habitats, while the communities composed of equilibrium species are often resource-limited and at, or near the carrying capacity of the environment.

Abiotic variables explained a lower degree of variability in the prevalence of the periodic strategy. This is likely due to its relatively moderate spatial contrast compared to the more pronounced spatial pattern of the equilibrium and opportunistic strategies throughout the study areas. Since we assess the strategies prevalence in the communities as proportions, the three strategies are related with each other: as one strategy proportion increase, the other decline. Therefore, the moderate response of the periodic strategy

to the environment might also be due to the fact that its relative proportion is affected by the more pronounced changes in the opportunistic and equilibrium strategies.

Fishing can impact community composition by affecting the relative abundance of both commercial and non-commercial species, as well as by physical impacts on the seabed (Myers \& Worm 2003, Hiddink et al. 2006). Fishing impacts on individual species is dependent on their traits and life history strategies (Jennings et al. 1999b, Winemiller 2005). As fishing increases disturbance, it will most likely benefit opportunistic species while disadvantaging the equilibrium species (Jennings et al. 1999b, Stevens et al. 2000). In our study, we found a negative effect of fishing effort on the prevalence of the equilibrium strategy. This negative relationship is expected, as equilibrium species, e.g. sharks and rays, are particularly vulnerable to fishing and habitat disturbance due to their low productivity arising from their life history characteristics, e.g. low fecundity and slow growth (Dulvy et al. 2008, Sguotti et al. 2016). Although the variability explained by the final model was low, the negative relationship with fishing is supported by the temporal changes in the equilibrium strategy in the North Sea, where it has increased since the 1980s, in synchrony with a general decrease in fishing effort. Recent findings showing that the decline in fishing effort in the 
North Sea and the neighbouring Kattegat coincided with an increase in the number of large fish in the communities (Fock et al. 2013, Engelhard et al. 2015; Lindegren et al. 2012) also support this explanation.

401

402

403

404

405

406

Life history strategies permit trait information to be reduced into a few ecologically-meaningful components. Our empirical findings of marine fish communities clearly support the theoretical framework by Winemiller and Rose (1992) demonstrating three main life-history strategies of fish: opportunistic, equilibrium and periodic. The proportion of the strategies showed pronounced spatio-temporal patterns across European Seas in response to varying environmental conditions. This highlights the underlying ecological mechanisms whereby fitness is optimized through natural selection, conditioned on the key trade-offs between growth, feeding and reproduction that ultimately determine the success or failure of a given life-history strategy under certain environmental conditions. However, our study also show that while marine fish communities can be characterized by three life-history strategies, a significant fraction of species do not abide strictly to any given strategy but rather reflect a combination of strategies. Interestingly, this is particularly evident for a number of small-pelagic species primarily distributed along the axis from opportunistic to periodic strategies (e.g., sprat, herring and mackerel). Although size is arguably a strong predictor of the position of species along a life-history continuum (Brown and Sibly 2006), it should be worthwhile exploring other more proximate traits explaining the presence and success of these intermediate strategies (Sibly and Brown 2007). In terms of marine fish, one such trait might be swimming performance which determines the range and extent of migratory behaviour and that ultimately allow species to successfully explore, forage and reproduce in very different habitats across pronounced environmental gradients. This may suggest that while for sedentary species it may be advantageous to more closely follow a given strategy, highly mobile species may rather optimize fitness through intermediate strategies, reflecting a compromise between the traits and trade-offs suitable across a large range of environments. Finally, we wish to stress that life history strategies can be implemented in various type of studies, e.g. to investigate population dynamics (Mims \& Olden 2012), colonization (Olden et al. 2006), fisheries management (King \& McFarlane 2003), or biological succession (Silvertown \& Franco 1993). 
Due to their strong dependence on the environment, life history strategies can therefore be a suitable management tool to deconstruct and characterize communities' composition and monitor changes in the communities in response to exploitation and climate change.

\section{Acknowledgments}

This work was funded by the Centre for Ocean Life, a VKR center of excellence supported by the Villum foundation, as well as a VILLUM research grant to ML (13159). This work has received funding from the European Community's Seventh Framework Programme (FP7 2007-2013) under grant agreement no. 308299 (NACLIM) and the European Union's Horizon 2020 research and innovation programme under grant agreement No 678193 (CERES, Climate Change and European Aquatic Resources). We acknowledge the

ICES Working Group on Comparative Analyses between European Atlantic and Mediterranean marine ecosystems to move towards an Ecosystem-based Approach to Fisheries (WGCOMEDA) during which the study was initiated and are thankful to all the WGCOMEDA participants for their valuable comments. The WGCOMEDA meeting was supported by a European Consortium EUROMARINE grant. We thank Georg Engelhard for the fishing effort data in the North Sea as well as Cefas project MF1228 Fizzyfish and STECF.

\section{Supporting Information}

Appendix S1 Information on the Bottom trawl surveys.

443 Appendix S2 Spatial patterns of the selected abiotic variables.

444 Appendix S3 Residuals sum of squares in function of the number of strategies.

445 Appendix S4 Species strategy: proportions expressed in each strategy.

446 Appendix S5 Spatial pattern and environmental predictors based on species presence. 
Appendix S6 Seasonality and life history strategies pattern in the North Sea.

Appendix S7 Fishing intensity and strategies' prevalence.

\section{Biosketches}

The work presented here was made possible thanks to collaboration between different European institute through the 'Working Group on Comparative Analyses between European Atlantic and Mediterranean marine ecosystems to move towards an Ecosystem-based Approach to Fisheries' (WGCOMEDA). Further information on the expert group activities can be found at www.ices.dk/community/groups/Pages/WGCOMEDA.aspx

The research was conducted primarily at the Centre for Ocean Life at the Technical University of Denmark, which uses the trait-based approach to study life in a changing ocean. Further information on the research group can be found at www.ocean-lifecentre.dk

\section{DATA ACCESSIBILITY}

The species list, their reproductive traits and their literature sources used for this study are available from the Pangaea database: https://doi.pangaea.de/10.1594/PANGAEA.868610.

\section{References}

Barton K (2016) Package MuMIn: Multi-model inference. :http://cran.rproject.org/web/packages/MuMIn/MuMIn

Bellwood DR, Hoey AS, Choat JH (2003) Limited functional redundancy in high diversity systems: resilience and ecosystem function on coral reefs. Ecology Letters 6:281-285

Bielby J, Mace GM, Bininda-Emonds ORP, Cardillo M, Gittleman JL, Jones KE, Orme CDL, Purvis A (2007) The fast-slow continuum in mammalian life history: an empirical reevaluation. The American Naturalist 169:748-757

Boyce MS (1979) Seasonality and patterns of natural selection for life histories. The American Naturalist 114:569-583 
Brown JH, Sibly RM (2006) Life-history evolution under a production constraint. Proceedings of the National Academy of Sciences 103:17595-17599

Cadotte M, Albert CH, Walker SC (2013) The ecology of differences: assessing community assembly with trait and evolutionary distances (A Mooers, Ed.). Ecology Letters 16:1234-1244

Charnov EL, Gislason H, Pope JG (2013) Evolutionary assembly rules for fish life histories. Fish and Fisheries $14: 213-224$

Collie JS, Wood AD, Jeffries HP (2008). Long-term shifts in the species composition of a coastal fish community. Canadian Journal of Fisheries and Aquatic Sciences, 65(7):1352-1365.

Cutler A, Breiman L (1994) Archetypal Analysis. Technometrics 36(4), 338-348.

Diaz S, Cabido M (2001) Vive la différence: plant functional diversity matters to ecosystem processes. Trends in Ecology \& Evolution 16:646-655

Dormann CF, Elith J, Bacher S, Buchmann C, Carl G, Carré G, Marquéz JRG, Gruber B, Lafourcade B, Leitão PJ, Münkemüller T, McClean C, Osborne PE, Reineking B, Schröder B, Skidmore AK, Zurell D, Lautenbach S (2013) Collinearity: a review of methods to deal with it and a simulation study evaluating their performance. Ecography 36:027-046

Dulvy NK, Baum JK, Clarke S, Compagno L V., Cortés E, Domingo A, Fordham S, Fowler S, Francis MP, Gibson C, Martínez J, Musick JA, Soldo A, Stevens JD, Valenti S (2008) You can swim but you can't hide: the global status and conservation of oceanic pelagic sharks and rays. Aquatic Conservation: Marine and Freshwater Ecosystems 18:459-482

Engelhard GH, Lynam CP, García-Carreras B, Dolder PJ, Mackinson S (2015) Effort reduction and the large fish indicator: spatial trends reveal positive impacts of recent European fleet reduction schemes. Environmental Conservation 42:227-236

Eugster MJ, Leisch F (2009) From spider-man to hero - archetypal analysis in R. Journal of Statistical Software 30:1-23

Eugster MJ a, Leisch F (2011) Weighted and robust archetypal analysis. Computational Statistics and Data Analysis 55:1215-1225

Flynn DFB, Mirotchnick N, Jain M, Palmer MI, Naeem S (2011) Functional and phylogenetic diversity as predictors of biodiversity-ecosystem-function relationships. Ecology 92:1573-81 
499

500

501

502

503

504

505

506

507

508

509

510

511

512

513

514

515

516

517

518

519

520

521

522

523

524 525

Fock HO, Kloppmann MHF, Probst WN (2013) An early footprint of fisheries: Changes for a demersal fish assemblage in the German Bight from 1902 - 1932 to 1991 - 2009. Journal of Sea Research 85:325-335

Franco M, Silvertown J (1996) Life history variation in plants: an exploration of the fast-slow continuum hypothesis. Proceedings of the National Academy of Sciences 351:1341-1348

Froese R, Pauly D (2012) Fishbase. World Wide Web Electronic Publication, 2012. www.fishbase.org

Grime JP (1977) Evidence for the Existence of Three Primary Strategies in Plants and Its Relevance to Ecological and Evolutionary Theory. The American Naturalist 111:1169-1194

Grizzetti B, Bouraoui F, Aloe A (2012) Changes of nitrogen and phosphorus loads to European seas. Global Change Biology 18:769-782

Gunderson DR (1997) Trade-off between reproductive effort and adult survival in oviparous and viviparous fishes. Canadian Journal of Fisheries and Aquatic Sciences 54:990-998

Halpern B, Floeter S (2008) Functional diversity responses to changing species richness in reef fish communities. Marine Ecology Progress Series 364:147-156

Hart Y, Sheftel H, Hausser J, Szekely P, Ben-Moshe NB, Korem Y, Tendler A, Mayo AE, Alon U (2015) Inferring biological tasks using Pareto analysis of high-dimensional data. Nature methods 12:233235

Hiddink JG, Jennings S, Kaiser MJ, Queirós AM, Duplisea DE, Piet GJ (2006) Cumulative impacts of seabed trawl disturbance on benthic biomass, production, and species richness in different habitats. Canadian Journal of Fisheries and Aquatic Sciences 63:721-736

ICES (2015) Report of the Working Group on Spatial Fisheries Data (WGSFD), 8-12 June 2015, ICES Headquarters, Copenhagen, Denmark. ICES CM 2015/SSGEPI:18. 150 pp.

Jennings S, Greenstreet SPR, Reynolds JD (1999a) Structural change in an exploited fish community: A consequence of differential fishing effects on species with contrasting life histories. Journal of Animal Ecology 68:617-627

Jennings S, Alvsvåg J, Cotter AJ., Ehrich S, Greenstreet SP., Jarre-Teichmann A, Mergardt N, Rijnsdorp A., Smedstad O (1999b) Fishing effects in northeast Atlantic shelf seas: patterns in fishing effort, 
diversity and community structure. III. International trawling effort in the North Sea: an analysis of spatial and temporal trends. Fisheries Research 40:125-134

Juan S De, Thrush SF, Demestre M (2007) Functional changes as indicators of trawling disturbance on a benthic community located in a fishing ground (NW Mediterranean Sea). Marine Ecology Progress Series 334:117-129

Juan-Jordá MJ, Mosqueira I, Freire J, Dulvy NK (2013) Life in 3-D: life history strategies in tunas, mackerels and bonitos. Reviews in Fish Biology and Fisheries 23:135-155

King JR, McFarlane G a. (2003) Marine fish life history strategies: applications to fishery management. Fisheries Management and Ecology 10:249-264

Lavorel S, Garnier E (2002) Predicting changes in community composition and ecosystem functioning from plant traits: revisiting the Holy Grail. Functional Ecology 16:545-556

Levinton JS (1970). The paleoecological significance of opportunistic species. Lethaia, 3:69-78.

Lindegren M, Blenckner T, Stenseth NC (2012) Nutrient reduction and climate change cause a potential shift from pelagic to benthic pathways in a eutrophic marine ecosystem. Global Change Biology, 18:3491-3503.

Litchman E, Ohman MD, Kiorboe T (2013) Trait-based approaches to zooplankton communities. Journal of Plankton Research 35:473-484

Longhurst A (2002) Murphy's law revisited: longevity as a factor in recruitment to fish populations. Fisheries Research 56:125-131

MacArthur R (1960). On the Relative Abundance of Species. The American Naturalist, 94(874):25-36.

Magurran AE, Dornelas M, Moyes F, Gotelli NJ, McGill B (2015) Rapid biotic homogenization of marine fish assemblages. Nature Communications 6:8405

McGill BJ, Enquist BJ, Weiher E, Westoby M (2006) Rebuilding community ecology from functional traits. Trends in Ecology \& Evolution 21:178-85

Mclntyre S, Lavorel S, Landsberg J, Forbes TDA (1999) Disturbance response in vegetation towards a global perspective on functional traits. Journal of Vegetation Science 10:621-630 
Mims MC, Olden JD (2012) Life history theory predicts fish assemblage response to hydrologic regimes. Ecology 93:35-45

Mims MC, Olden JD, Shattuck ZR, Poff NL (2010) Life history trait diversity of native freshwater fishes in North America. Ecology of Freshwater Fish 19:390-400

Mørup M, Hansen LK (2012) Archetypal analysis for machine learning and data mining. Neurocomputing 80:54-63

Myers RA, Worm B (2003) Rapid worldwide depletion of predatory fish communities. Nature 423:280-283

Neuheimer AB, Hartvig M, Heuschele J, Hylander S, Kiørboe T, Olsson K, Sainmont J, Andersen KH (2015) Adult and offspring size in the ocean over 17 orders of magnitude follows two life-history strategies. Ecology 96:3303-3311

Nichols JD, Conley W, Batt B, Tipton AR (1976) Temporally Dynamic Reproductive Strategies and the Concept of R- and K-Selection. The American Naturalist 110:995-1005

Núñez-Riboni I, Akimova A (2015) Monthly maps of optimally interpolated in situ hydrography in the North Sea from 1948 to 2013. Journal of Marine Systems 151:15-34

Olden JD, Leroy Poff N, Bestgen KR (2006) Life-history strategies predict fish invasions and extirpations in the Colorado River Basin. Ecological Monographs 76:25-40

Oli MK (2004) The fast-slow continuum and mammalian life-history patterns: An empirical evaluation. Basic and Applied Ecology 5:449-463

Pecuchet L, Lindegren M, Hidalgo M, Delgado M, Esteban A, Fock HO, Gil de Sola L, Punzón A, Sólmundsson J, Payne MR (2016a): Reproductive traits (Fecundity, egg diameter, parental care) of marine European fish. Dataset \#868610 (DOI registration in progress)

Pecuchet L, Törnroos A, Lindegren M (2016b) Patterns and drivers of fish community assembly in a large marine ecosystem. Marine Ecology Progress Series 546:239-248

Pepin P (1991) Effect of temperature and size on development, mortality and survival rates of the pelagic early life history satges of marine fish. Canadian Journal of Fisheries and Aquatic Sciences 48:503518 
Perry AL, Low PJ, Ellis JR, Reynolds JD (2005) Climate Change and Distribution Shifts in Marine Fishes. Science 308:1912-1915

Petchey OL, Gaston KJ (2002) Functional diversity (FD), species richness and community composition. Ecology Letters 5:402-411

Petchey OL, Gaston KJ (2006) Functional diversity: back to basics and looking forward. Ecology Letters 9:741-758

Pianka ER (1970) On r- and K-selection. American Naturalist 104:592-597

Schleuter AD, Daufresne M, Massol F, Argillier C, Monographs SE, August N (2010) A user 's guide to functional diversity indices. Ecological Monographs 80:469-484

Sguotti C, Lynam CP, García-Carreras B, Ellis JR, Engelhard GH (2016) Distribution of skates and sharks in the North Sea: 112 years of change. Global Change Biology 22:2729-2743

Shipley B, Vile D, Garnier E (2006) From Plant Traits to Plant Communities: A Statistical Mechanistic Approach to Biodiversity. Science 314:812-814

Sibly RM, Brown JH (2007) Effects of body size and lifestyle on evolution of mammal life histories. Proceedings of the National Academy of Sciences 104:17707-17712

Silvertown J, Franco M (1993) Plant Demography and Habitat: A Comparative Approach. Plant Species Biology 8:67-73

Stevens J, Bonfil R, Dulvy NK, Walker PA (2000) The effects of fishing on sharks, rays, and chimaeras (chondrichthyans), and the implications for marine ecosystems. ICES Journal of Marine Science 57:476-494

Tsoukali S, Olsson KH, Visser AW, MacKenzie BR (2016) Adult lifetime reproductive value in fish depends on size and fecundity type. Canadian Journal of Fisheries and Aquatic Sciences 73:1405-1412

Violle C, Navas M-L, Vile D, Kazakou E, Fortunel C, Hummel I, Garnier E (2007) Let the concept of trait be functional! Oikos 116:882-892

Warton DI, Hui FKC (2011) The arcsine is asinine: the analysis of proportions in ecology. Ecology 92:3-10 
603 Wiedmann M a., Primicerio R, Dolgov A, Ottesen C a. M, Aschan M (2014) Life history variation in Barents 604 Sea fish: implications for sensitivity to fishing in a changing environment. Ecology and Evolution 605 4:3596-3611

606 Winemiller KO (1989) Patterns of variation in life history among South American fishes in seasonal $607 \quad$ environments. Oecologia 81:225-241

608 Winemiller KO (2005) Life history strategies, population regulation, and implications for fisheries 609 management. Canadian Journal of Fisheries and Aquatic Sciences 62:872-885

Winemiller KO, Fitzgerald DB, Bower LM, Pianka ER (2015) Functional traits, convergent evolution, and periodic tables of niches. Ecology Letters 18:737-751

Winemiller KO, Rose KA. (1992) Patterns of Life-History Diversification in North American Fishes: implications for Population Regulation. Canadian Journal of Fisheries and Aquatic Sciences 49:2196-2218

615 Wood SN (2006) Generalized additive models: an introduction with R. CRC press 
617 Table 1. Variables and parameters of the best final generalized additive mixed models (gamm), 618 with a maximum of three abiotic variables and corrected for the sampling effort. $\mathrm{R}^{2}$ is the adjusted $619 R^{2}$ of the final model and RVI is the estimated relative variable importance of each variable present 620 in the final model, it corresponds to the drop in the model $\mathrm{R}^{2}$ when the variable is randomized. All 621 variables in the final model are significant $(p<0.001)$. SST refers to sea surface temperature, SST 622 seasonality to the seasonality in sea surface temperature, Depth to the mean depth of the hauls 623 performed and $\mathrm{CHL}$ to the chlorophyll a concentration.

\begin{tabular}{|c|c|c|c|}
\hline Life history strategies & Best model & $\mathrm{R}^{2}$ & RVI \\
\hline \multirow{4}{*}{ Opportunistic } & SST + SST seasonality + CHL & 0.78 & \\
\hline & SST & & 0.38 \\
\hline & SST Seasonality & & 0.34 \\
\hline & $\mathrm{CHL}$ & & 0.26 \\
\hline \multirow{4}{*}{ Periodic } & SST + Depth + SST seasonality & 0.53 & \\
\hline & SST & & 0.13 \\
\hline & Depth & & 0.12 \\
\hline & SST Seasonality & & 0.09 \\
\hline \multirow{4}{*}{ Equilibrium } & SST seasonality + SST + Depth & 0.70 & \\
\hline & SST Seasonality & & 0.20 \\
\hline & SST & & 0.09 \\
\hline & Depth & & 0.04 \\
\hline
\end{tabular}


Figure 1. Plot of the first and second principal component (PC1 and PC2) based on a principal component analysis (PCA) on the six selected traits. Each species used in the study is represented by a black dot. The three extreme points (archetypes) that encompass the trait-space are represented by black crosses, corresponding to the equilibrium, opportunistic and periodic strategies, respectively. Furthermore, each of the strategies are illustrated by one characteristic species marked by grey dots, namely cod (Gadus morhua) a periodic species, sand goby (Pomatoschistus minutus) an opportunistic species, and school shark (Galeorhinus galeus) an equilibrium species.

Figure 2. Proportion of the life history strategies (left) equilibrium, (middle) opportunistic and (right) periodic in each $1 / 2$ degree cell across the European Seas calculated from species abundance. At each grid cell, the sum of the three life history strategies proportion adds to one. The top panel represents Greenland and Iceland while the bottom panel shows Western Europe. On the bottom left panel, the black triangle represents the location of the North Sea, the ecosystem used in the temporal case study.

Figure 3. Relationships between the life history strategies proportion in the communities and their environmental predictors retained in the best gam model. SST refers to sea surface temperature, SST season to the seasonality in sea surface temperature.

Figure 4. Time series of relative proportions of equilibrium (black), opportunistic (dark grey) and periodic strategies (grey) in the North Sea from 1980 to 2014 (top panel). The lower panels show the concomitant trends in sea surface temperature (SST) and SST seasonality for 1980-2014 (middle) and fishing effort by otter- and beam trawlers for 1991-1995 and 2003-2012 (bottom). The regression lines and their confidence interval (shaded area) are displayed when the temporal pattern is significant at $p<0.05$. Due to different scale, the fishing effort and temperature variables were standardized to facilitate the comparison. 


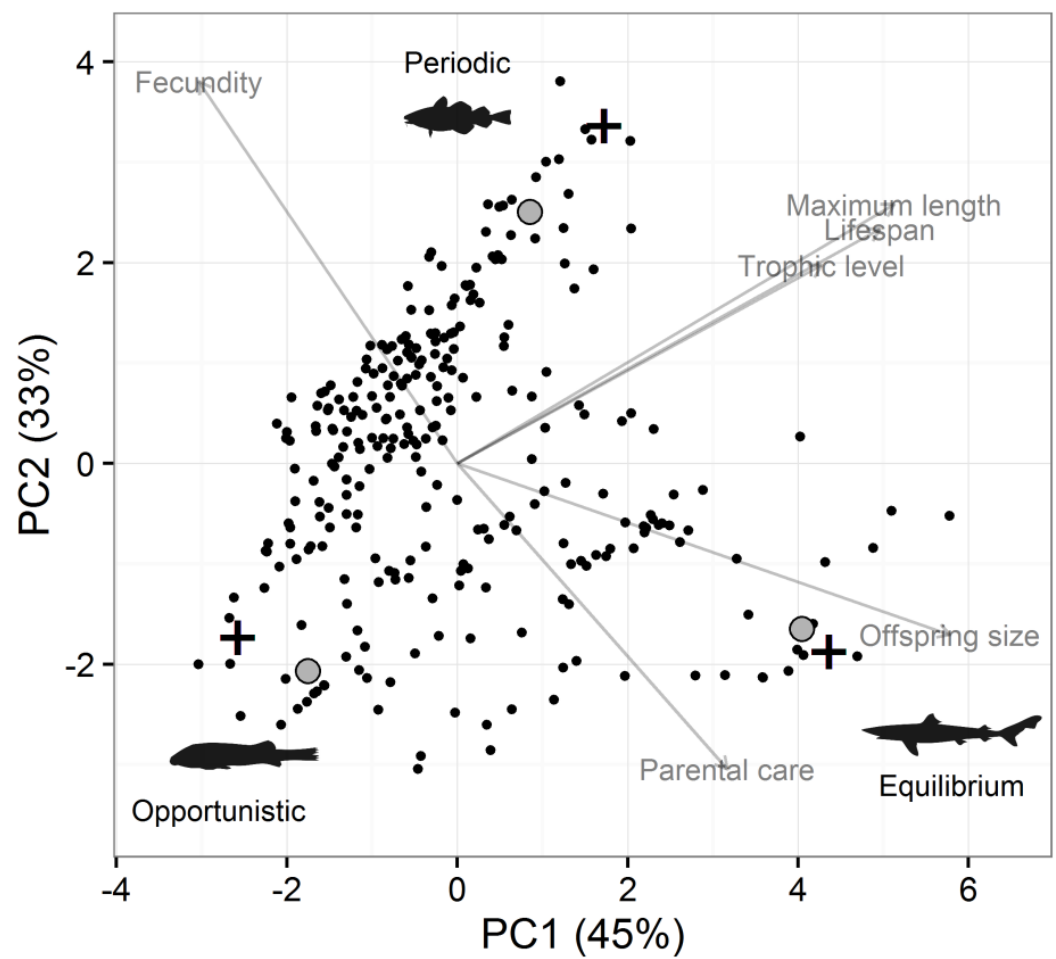

652 Figure 1 

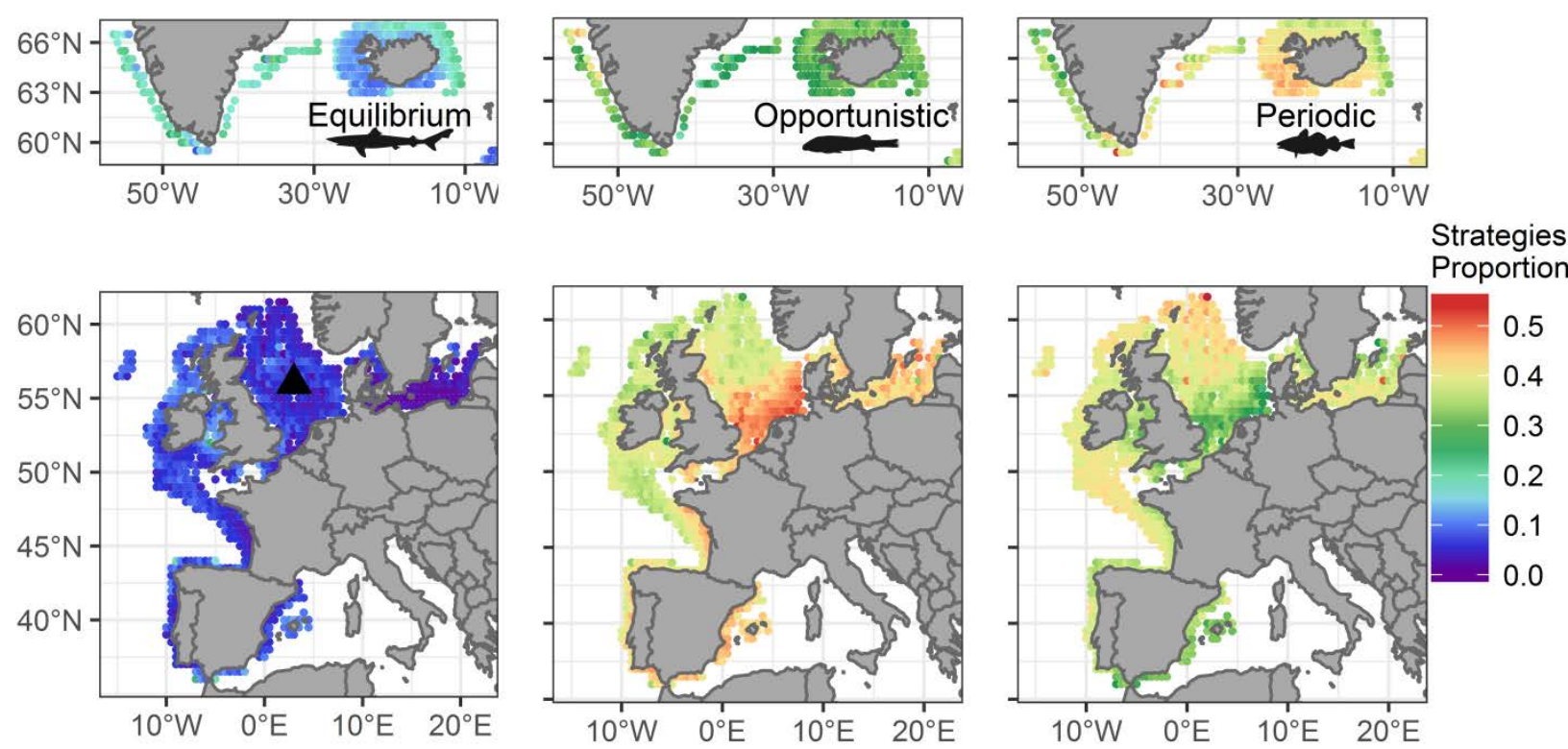

654

655 Figure 2. 

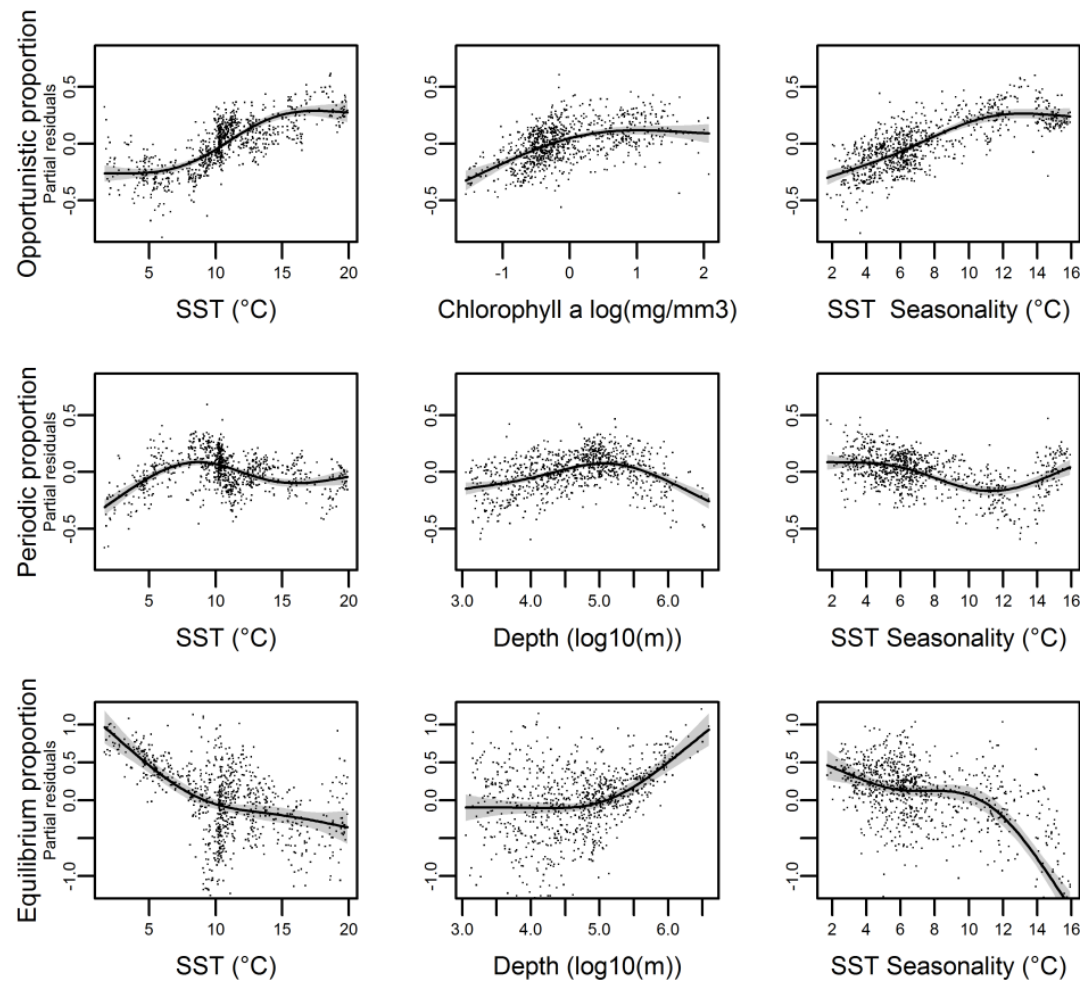

658 Figure 3. 

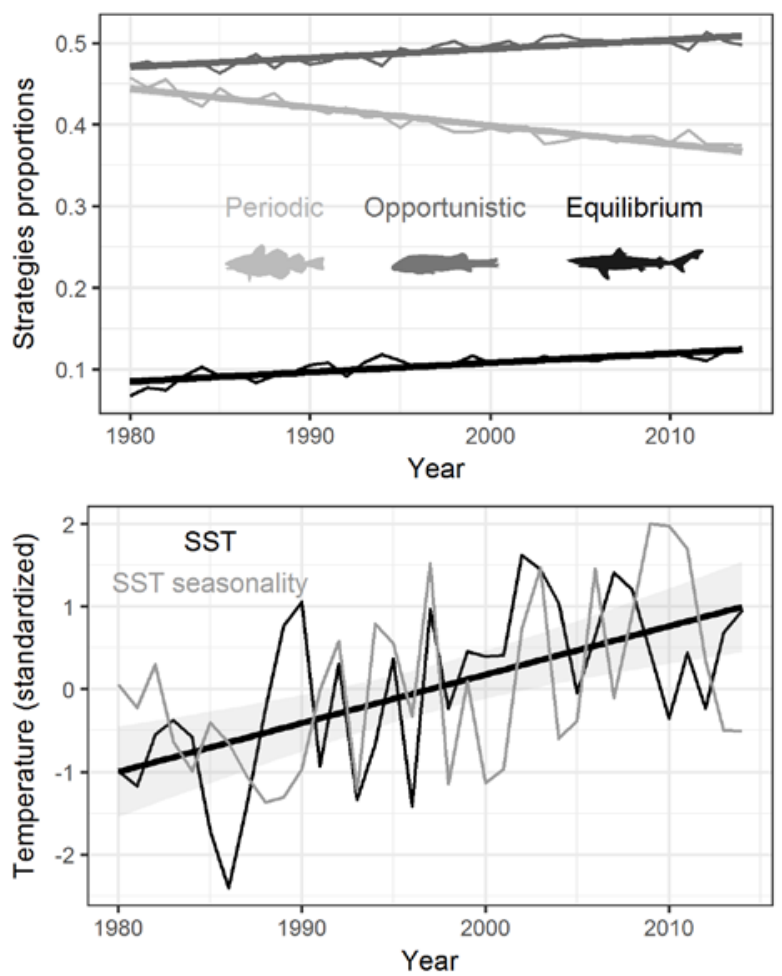

659

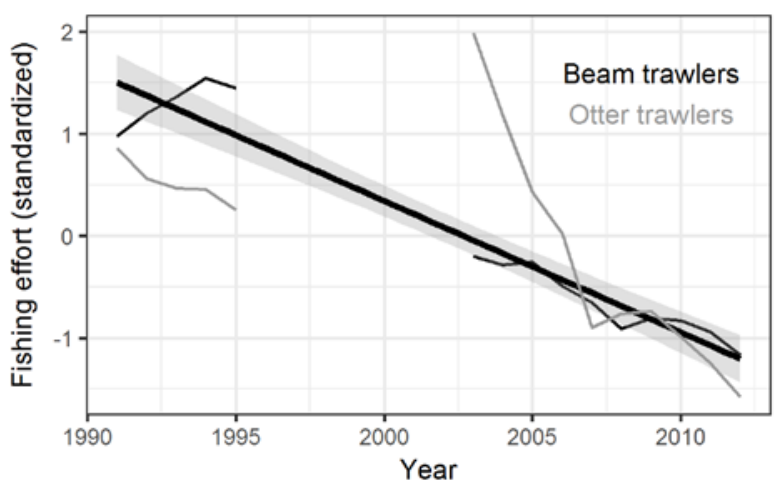

660 Figure 4. 